\title{
Analysis of the Correlation between Collagen and Desoxyribonucleic Acid Syntheses under the Influence of Hydroxyurea in the Inflammatory Connective Tissue
}

\author{
Kun Hyun Shin, ${ }^{1 a}$ ) Hideo Nakagawa, and Susumu Tsurufuji ${ }^{1)}$ \\ Pharmaceutical Institute, Tohoku University ${ }^{1)}$
}

(Received February 24, 1976)

\begin{abstract}
A significant inhibition of desoxyribonucleic acid (DNA) synthesis in rat granuloma cells was brought about by 6 repeated administrations $(250 \mathrm{mg} / \mathrm{kg}$ ) of hydroxyurea at $12 \mathrm{hr}$ intervals from day 5 to day 7 after carrageenan injection. The suppressive effect of hydroxyurea on the amount of DNA in granulomatous tissue began to appear on day 8 (12 $\mathrm{hr}$ after the last injection of hydroxyurea), and then a maximum inhibition was attained on day 9. The inhibitory effect on the amount of collagen, on the other hand, was disclosed on day 9 with the retardation of around one day to the appearance of suppressive effect on DNA.

The cellular activity for collagen synthesis in the hydroxyurea-treated group was gradually elevated accompanying coincidental suppression of DNA synthesis, suggesting that mature cells synthesized collagen more actively than newly formed cells. Suppression of cell proliferation by hydroxyurea seems to result in decrease in the number of mature cells with the retardation of time required for maturation of newly formed cells.
\end{abstract}

\section{Introduction}

Collagen, on account of its abundance in the animal body and likely importance in connective tissue diseases, has aroused a great interest as an object for study in proliferative inflammation. We have reported a series of papers ${ }^{2)}$ concerning anti-inflammatory activities of glucocorticoids, which inhibit proliferative phases of the inflammation and induce a marked involution of pre-existing granuloma. However, it was demonstrated in a previous paper ${ }^{2 h}$ that the cessation of glucocorticoid treatment caused sudden recurrence of the granulomatous inflammation, resulting in a rapid recovery of the DNA, collagen and non-collagen protein synthesizing activities of granuloma cells. In the course of such a recurrence of the granulomatous inflammation, the reactivation of collagen synthesis occurred with a retardation of 1 or 2 days compared with that of DNA synthesis. ${ }^{2 h}$ ) This retardation seemed to indicate that the collagen-synthesizing activity of newly formed fibroblasts was lower than that of mature fibroblasts and it took 1 or 2 days for the maturation of newly formed fibroblasts. In an attempt to obtain further evidence for this concept of the maturation of cells synthesizing collagen, the effect of the inhibition of DNA synthesis on the collagen-synthesizing activity of granuloma cells was investigated in vivo by using hydroxyurea, a specific inhibitor of DNA synthesis. ${ }^{3)}$

1) Location: Aobayama, Sendai; a) Present address: Natural Products Research Institute, Seoul National University, Seoul, Korea. Please address reprint requests to $\mathrm{H}$. Nakagawa.

2) a) M. Fukuhara and S. Tsurufuji, Biochem. Pharmac., 18, $475(1969)$; b) M. Fukuhara and S. Tsurufuji, ibid., 18, 2409 (1969); c) T. Ohno and S. Tsurufuji, ibid., 19, 1 (1970); d) H. Nakagawa and S. Tsurufuji, ibid., 21, 893 (1972); e) H. Nakagawa, M. Fukuhara, and S. Tsurufuji, ibid., 20, $2253(1971)$; f) T. Ohno, S. Ishibashi, and S. Tsurufuji, ibid., 21, $1057(1972) ; g)$ H. Nakagawa and S. Tsurufuji, ibid., 21, 1884 (1972); h) K.H. Shin, H. Nakagawa, and S. Tsurufuji, ibid., 23, 381 (1974).

3) H.S. Rosenkranz and L.A. Levy, Biochim. Biophys. Acta, 95, 181 (1965); C.W. Young and S. Hodas, Science, 146, 1172 (1964); J.W. Yarbro,W.G. Niwhaus, and C.P. Barnum, Biochem. Biophys. Res. Comm., 19, 592 (1965). 


\section{Materials and Methods}

Treatments of Animals____ Young male rats of the Donryu strain, ranging body weight from 130 to $150 \mathrm{~g}$, were used. Granuloma pouch was induced by injecting a $2 \%$ solution of Seakem 202 carrageenan according to a previous paper. ${ }^{2} \alpha$ ) The animals were maintained in a fixed-temperature environment $\left(23 \pm 1^{\circ}\right)$ and with free access to food (Funabashi Inc., Chiba) and water. On day 5 after carrageenan injection, the animals bearing granuloma pouch were divided into two groups; one was treated with repeated injections of hydroxyurea and the other served as control. The grouping of animals was done so as to hold uniformity between groups with respect to the size of the granuloma pouch and body weight of animals at the beginning of the treatment.

Hydroxyurea, at a dose of $250 \mathrm{mg} / \mathrm{kg}$ in a volume of $0.4 \mathrm{ml}$ of $0.9 \% \mathrm{NaCl}$, was repeatedly administered at $12 \mathrm{hr}$ intervals into the granuloma pouch from day 5 to day 7 after carrageenan injection. Hydroxyurea solution was prepared just before injection in order to avoid its possible decomposition. Pair-feeding was performed by keeping animals in individual cages in order to synchronize the body weight change of the control rats with that of hydroxyurea-treated animals, since the body weight gain of the drug treated animals was suppressed slightly. The animals were sacrificed by cutting carotid artery at days $6,7,9$, and 10 in the first experiment, and at days $8,11,12$, and 13 in the second experiment. The granuloma was harvested and weighed.

Incubation of the Granuloma_- The harvested granuloma was minced into small pieces and an aliquot $(1 \mathrm{~g})$ of the minced granuloma was incubated at $37^{\circ}$ for $2 \mathrm{hr}$ under $95 \% \mathrm{O}_{2}-5 \% \mathrm{CO}_{3}$ in $10 \mathrm{ml}$ of Krebs' saline serum substitute ${ }^{4}$ containing $5 \mu \mathrm{Ci}$ of $\left[{ }^{3} \mathrm{H}\right]$-L-proline (generally labeled, $63 \mathrm{Ci} / \mathrm{mmole}$ ). The reaction was stopped by adding $50 \%$ trichloroacetic acid to give a $10 \%$ final concentration and $0.1 \mathrm{ml}$ of cold $1 \% \mathrm{~L}$-proline was added as a scavenger. The mixture was chilled and centrifuged at $3500 \mathrm{rpm}$ for $15 \mathrm{~min}$. The precipitate was washed four more times with each $30 \mathrm{ml}$ of $75 \%$ ethanol. Collagen was extracted twice as gelatin by autoclaving the precipitate at $120^{\circ}$ for $1 \mathrm{hr}$ with $20 \mathrm{ml}$ of distilled water. An aliquot of the gelatin was hydrolyzed in $6 \mathrm{~N} \mathrm{HCl}$ at $105^{\circ}$ for $16 \mathrm{hr}$. Hydroxyproline of the hydrolysate was measured by the method of Kivirikko, et al.5) and the amount of collagen was expressed in terms of the quantity of hydroxyproline. The radioactivity of collagen hydroxyproline was measured after converting hydroxyproline into pyrrole, which was purified by passing through a silicic acid column.,6) The cellular activity for collagen synthesis was expressed as the radioactivity of collagen hydroxyproline per mg DNA of the tissue.

Determination of DNA-For the measurement of DNA, another aliquot $(1 \mathrm{~g})$ of the minced granuloma was homogenized and extracted by a modification of Schmidt-Thannhauser-Schneider method. ${ }^{2 h}$ ) DNA was determined by the Burton's method?) using calf thymus DNA as a reference standard.

\section{Results and Discussion}

The overall changes from day 6 to day 13 in the wet weight and in the amounts of collagen and DNA of the granuloma from rats treated with hydroxyurea are shown in Fig. 1, 2 and 3, respectively. On day 9 the wet weight and the total amount of collagen of the granuloma were significantly decreased by the hydroxyurea treatment, and thereafter both the values of the hydroxyurea-treated group gradually recovered to the control levels with the passage of time (Fig. 1 and 2). Total amounts of DNA in the control granuloma increased gradually and reached a maximum on day 11, and then declined (Fig. 3). The suppressive effect of hydroxyurea on the amount of DNA was undetected during initial 2 days of experimental period, but subsequently it became apparent and significant on day 8 . Thereafter until the end of the experimental period the treated group took lower level than the control (Fig. 3). A maximum inhibitory effect of hydroxyurea on the DNA content was attained on day 9 and then the amount of DNA gradually approached up to the control level with the passage of time. On the other hand, the inhibitory effect of hydroxyurea on the amount of collagen was disclosed on day 9 with the retardation of around one day to the appearance of suppressive effect on DNA (Fig. 2 and 3).

As shown in Fig. 4, on day 9 collagen-synthesizing activity of granuloma cells was significantly increased by hydroxyurea treatment. "This increase of collagen synthesis occurred

4) H.A. Krebs, Biochim. Biophys. Acta, 4, 249 (1950).

5) K.I. Kivirikko, O. Laitinen, and D.J. Prockop, Analyt. Biochem., 19, 249 (1967).

6) K. Juva and D.J. Prockop, Analyt. Biochem., 15, 77 (1966).

7) K. Burton, Biochem. J., 62, 315 (1956). 


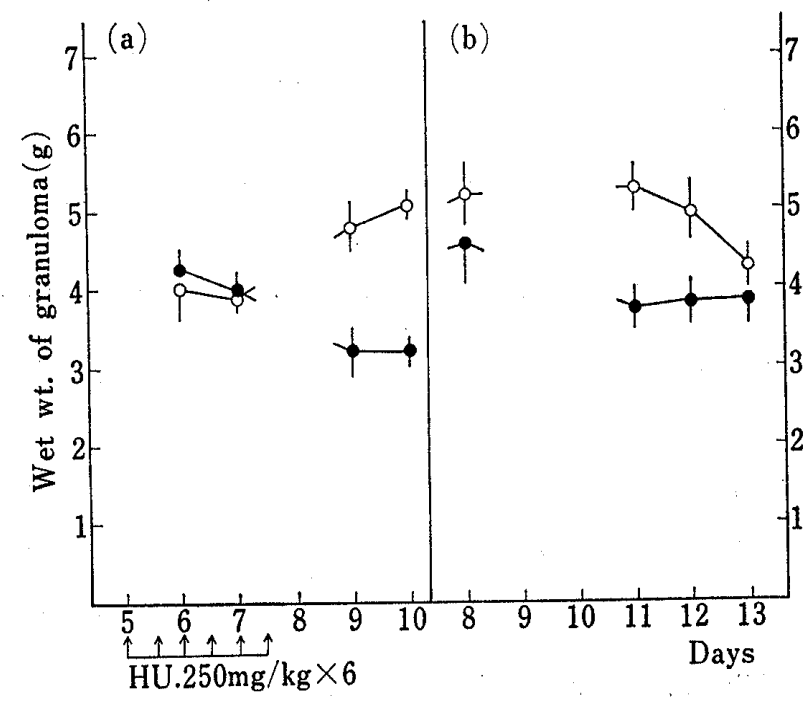

Fig. 1. Effect of Hydroxyurea on the Wet Weight of Carrageenan Granuloma

Hydroxyurea (HU) was injected directly into the pouch at $12 \mathrm{br}$ intervals from day 5 to day 7 ( 6 injections in total). The granulomatous tissue was harvested on days $6,7,9$. and 10 (a; Expt. 1), and on days \&, 11, 12 and 13 (b; Expt. 2). Each point is the mean of 5 animals. A vertical line at each point represents the S.E. of the mean. $1 O-O$, control; hydroxyurea-treated) coincidentally with the decrease in the amount of DNA. On the other hand, its returning down to the control level also coincided with the gradual increase in the DNA level at the end of experimental period.

In order to summarize the overall changes with the passage of time in the total amounts of DNA and collagen and in the cellular activity for collagen synthesis, the values of hydroxyureatreated group was expressed in terms of percentage of the values of respective controls (Fig. 5). As shown in Fig. 5, significant suppression of the DNA content arose at last on day $8(60 \mathrm{hr}$ after the first injection of hydroxyurea). As the mechanism of inhibitory action of hydroxyurea on DNA synthesis is to block the enzymatic reduction of the ribonucleotide to the deoxyribonucleotide, ${ }^{8)}$ the above mentioned latency of the action of hydroxyurea may be explained by assuming that the latent period would have been a time to consume preexisting deoxyribonucleotide pool of the cell. Hydroxyurea has been known as a specific inhibitor of DNA synthesis with little direct action on protein synthesis. ${ }^{3)}$ In the present study, it was demonstrated that a marked decrease of DNA content was brought about on day 8,

8) R.L.P. Adams and J.G. Lindsay, J. Biol. Chem., 242, 1314 (1967); G.R. Gale, Experientia, 24, 57. (1968); C.W. Young, G. Schochetman, and D. Karnofsky, Cancer Res., 27, 526 (1967). 

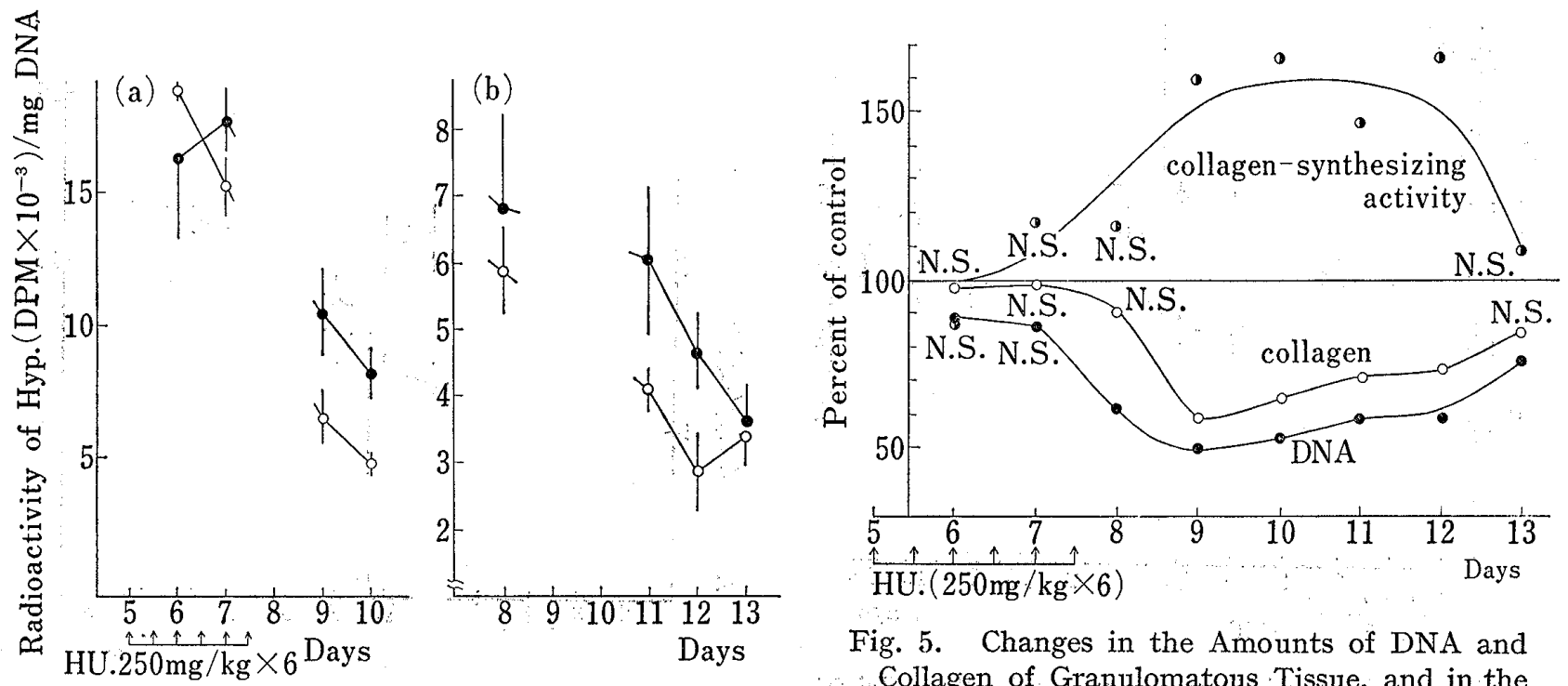

Fig. 4. Effect of Hydroxyurea on the Incorporation of $\left[{ }^{3} \mathrm{H}\right]$ proline into Collagen Hydroxyproline

Each point is the mean of 5 aninals. A vertical line at each point represents S.E. of the mean. $(\mathrm{O}-\mathrm{O}$, control hydroxyurea-treated!

Fig. 5. Changes in the Amounts of DNA and Collagen of Granulomatous Tissue, and in the Collagen-synthesizing Activity of the Cells

Fig. 2, 3, and 4 were summarized in this figure by expressing the each values of hydroxyurea-treated group as a percent of those of the respective controls. N.S. = not significant

while no significant decrease in the amount of collagen was found at that time. It is unlikely, therefore, that hydroxyurea exerted a direct action on collagen synthesis. Moreover, on day 9 the collagen-synthesizing activity of granuloma cells was significantly increased, although proliferation of the cells was markedly suppressed by hydroxyurea. Such an enhancement of collagen-synthesizing activity of granuloma cells coincided with the inhibition of DNA synthesis. If the number of newly formed cells in the granuloma is reduced by the inhibition of DNA synthesis, the proportion of mature cells is expected to become higher. Thus, it seems that mature cells synthesize collagen more actively than newly formed cells. Goldberg and $\mathrm{Green}^{9}$ ' also demonstrated that mouse fibroblasts (cell line 3T6) did not synthesize collagen during log phase in cell culture, while collagen synthesis began upon cessation of growth (stationary phase). Gibble, et al. ${ }^{10}$ showed that increased collag $\mathrm{n}$ synthesis in cell culture was accompanied by a sharp increase in the activity of polyl hydroxylase. It was subsequently shown that the increased activity in cellular prolyl hydroxylase was not due to formation of new enzyme but to the activation of an already existing enzyme. ${ }^{11}$ ) Comstock and Udenfriend ${ }^{12)}$ demonstrated that an increase in the activity of prolyl hydroxylase in early log-phase fibroblasts could be induced by the administration of sodium lactate, suggesting that lactate may play an important role as an activator of the enzyme. Since lactate concentration increases in cells as they normally enter the stationary phase, ${ }^{13)}$ the increased collagen synthesis in the present experiments might be due to an activator of prolyl hydroxylase such as lactate.

In the present experiments; there is a time gap of about one day from day 8 to day 9 between DNA and collagen regarding the occurrence of suppression in the total amount of these two components (Fig. 5). These results could be explained reasonably by assuming that it takes around one day for the maturation of newly formed cells into actively collagen-

9) B. Goldberg and H. Green, J. Cell Biol., 22, 227 (1964).

10) T.J. Gribble, J.P. Comstock, and S. Udenfriend, Arch. Biochem. Biophys., 129, 308 (1969).

11) J. O'D. McGee, U. Langness, and'S. Udenfriend, Proc. Nat. Acad. Sci, 68, 1585 (1971).

12) J.P. Comstock and S. Udenfriend, Proc. Nat. Acad. Sci., 66, 552 (1970).

13) W.S. Bullough and E.B. Lawrence," "Wound Healing," ed. by D. Slome, Pergamon Press, London, 1961, p. 1. 
synthesizing cells. The results described above also agreed with the finding reported in a previous paper $^{2 h}$ that the induction of collagen synthesis occurred with a retardation of 1 or 2 days to the reac ivation of DNA synthesis in the course of reactivation of granulomatous inflammation up $\mathrm{n}$ withdrawal of glucocorticoid treatments. 